\title{
Magnesium diminishes the electrical double layer forces between carbonate particles
}

\author{
MARZENA PRUS, ${ }^{1}$ KAROLINA KĘDRA-KRÓLIK, ${ }^{1}$ \\ KAROLINA SZYMANEK, ${ }^{2}$ WOJCIECH PIASECKI, ${ }^{2}$ \\ PIOTR ZARZYCKI ${ }^{3,1}$
}

${ }^{1}$ Institute of Physical Chemistry, Polish Academy of Sciences, Warsaw, Poland; ${ }^{2}$ Department of Chemistry and Biochemistry, AWF, Warsaw, Poland; ${ }^{3}$ Energy Geosciences Division, Lawrence Berkeley National Laboratory, Berkeley, CA

Carbonates dominate sediments and sedimentary rocks in the Earth's crust. Their formation and evolution in aqueous solutions are closely linked to the development of the electrical double layer at their surface [1]. However, our experimental insight into the role of the electrical double layer forces in carbonate nucleation remains limited [2,3] especially in complex solutions with several interfering, coprecipitating, and adsorbing ions.

Here, we show how the electrical double layer (EDL) formed at the carbonate/electrolyte interface in the presence of $\mathrm{Mg}^{2+}$ evolves in time by using time-resolved electrophoresis and potentiometry [3]. The presence of $\mathrm{Mg}^{2+}$ ions not only stabilizes metastable carbonate phases - such as vaterite - but also diminishes the magnitude of the repulsive EDL forces. The first effect has been previously observed and it is usually attributed to the large dehydration energy barrier for $\mathrm{Mg}^{2+}$ ions [4], the second one has not been studied yet.

Our results suggest that $\mathrm{Mg}^{2+}-$ and other additives - can affect not only the carbonate nucleation pathways, but also sediment stability via the additional screening of the longrange electrostatic forces.

[1] Heberling F., et al. (2011) Journal of Colloid and Interface Science 354, 843-857.

[2] Dziadkowiec J., et al. (2019) Sci Rep, 1-15.

[3] Prus M., et al. (2019) Journal of Colloid and Interface Science 544, 249-256.

[4] Davis K. J. et al. (2000) Science 290, 1134-1137. 